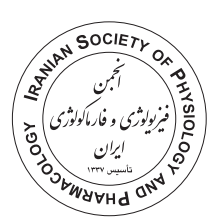

\title{
High-dose fluoxetine improved long-term potentiation of the hippocampal dentate gyrus in male rats
}

\author{
Siamak Shahidi' ${ }^{1}$ Leila Rabiee ${ }^{1}$, Alireza Komaki ${ }^{2,1}$, Reihaneh Sadeghian ${ }^{3 *}$ (DD)
}

1. Department of Physiology, School of Medicine, Hamadan University of Medical Sciences, Hamadan, Iran

2. Neurophysiology Research Center, Hamadan University of Medical Sciences, Hamadan, Iran

3. Medical Plants Research Center, Basic Health Sciences Institute, Shahrekord University of Medical Sciences, Shahrekord, Iran

\section{ABSTRACT}

Introduction: Paradoxical data have been reported regarding the effects of fluoxetine on different types of learning and memory. Hippocampus-dependent memory is mediated by long-term potentiation (LTP). Here, we evaluated the effects of acute administration of fluoxetine on LTP induction in the hippocampal dentate gyrus of intact rats.

Methods: Eighteen rats were divided into three groups: the control group received saline $15 \mathrm{~min}$ before high-frequency stimulation (HFS) and the fluoxetine groups were treated with fluoxetine ( 2 or $10 \mathrm{mg} / \mathrm{kg}$ ), $15 \mathrm{~min}$ before HFS. The rats were anesthetized with urethane and put in a stereotaxic system for surgery, electrode implantation and field recording. After ensuring a steady-state baseline response, a single intraperitoneal injection of saline or fluoxetine ( 2 or $10 \mathrm{mg} / \mathrm{kg}$ ) was done. Next, population spike amplitude, excitatory postsynaptic potential (EPSP) slope, and paired-pulse stimuli (to determine recurrent inhibitory interneuron) were measured in the hippocampal dentate gyrus in three groups.

Results: The results showed that population spike amplitude markedly increased in the fluoxetine ( 2 and $10 \mathrm{mg} / \mathrm{kg}$ ) group than in the saline group. Also, EPSP slope induction in the fluoxetine $(10 \mathrm{mg} / \mathrm{kg})$ group showed an increase, 60min after HFS compared with the control group. Fluoxetine did not significantly affect recurrent inhibition.

Conclusion: These results indicated that the acute administration of high-dose fluoxetine $(10 \mathrm{mg} / \mathrm{kg})$ can induce LTP. Thus, fluoxetine can be considered as a memory enhancer in intact rats.

\section{Introduction}

Serotonin or 5-hydroxytryptamine (5-HT) is a monoamine neurotransmitter, which plays a key role in modulating behavior (Bacqué-Cazenave et al., 2020; Shahidi

\author{
Keywords: \\ Fluoxetine \\ Selective serotonin reuptake in- \\ hibitors \\ Long-term potentiation \\ Hippocampus
}

et al., 2018b). In the nervous system, this neurotransmitter has many functions, such as learning and memory as well as synaptic plasticity of the nervous system (Shahidi et al., 2019b). The majority of serotonin receptors

\footnotetext{
* Corresponding author: Reihaneh Sadeghian, sadeghian.r@skums.ac.ir

Received 21 October 2020; Revised from 11 January 2021; Accepted 25 January 2021
}

Citation: Shahidi S, Rabiee L, Komaki A, Sadeghian R. High-dose fluoxetine improved long-term potentiation of the hippocampal dentate gyrus in male rats. Physiology and Pharmacology 2021; 25: 223-230. http://dx.doi.org/10.52547/ppj.25.3.223 
are $\mathrm{G}$ protein-coupled receptors and trigger intracellular signaling cascades that can trigger long-term changes in neuronal activity resulting in behavioral changes (Catapano and Manji, 2007).

Fluoxetine, a selective serotonin reuptake inhibitor, induces a temporary rise in serotonin levels in the nervous system synapses. Environmentally relevant concentrations of antidepressants can alter intracellular signaling pathways, memory and cognitive capacity (Hamilton et al., 2016); however, major gaps still exist in our understanding of how this drug affects the brain (Keith et al., 2007). It is demonstrated that fluoxetine modulates acute and chronic psychological diseases (Kobayashi et al., 2008).

One of the most important challenges of neuroscience is to identify cellular and molecular processes underlying learning and memory formation (Lynch, 2004). Although several areas of the brain play a role in integrating multiple forms of memory, the hippocampus plays a vital role in memory formation (Molaei et al., 2020; Sadeghian et al., 2012). Long-term potentiation (LTP) has been reported to be the most extensive memory storage mechanism in the hippocampus and neocortex (Baudry, 2001). However, for decades, the LTP memory hypothesis with conflicting evidence has remained highly controversial (Dringenberg, 2020).

There are conflicting reports on the effect of fluoxetine on memory and learning in human and laboratory animals. Fluoxetine improves learning and memory in depressed patients as well as animals (Marwari and Dawe, 2018). However, some studies have shown that fluoxetine has no effect on learning and memory in laboratory animals (Pawluski et al., 2014) and paradox reports indicated a reduction in learning and memory in fluoxetine-treated samples, including patients and experimental animals (Pawluski et al., 2014; Valluzzi and Chan, 2007). This difference may be due to variation in learning and memory or different used samples (Pawluski et al., 2014).

The effect of fluoxetine on LTP is contradictory in various studies. Some reports have stated that the fluoxetine impairs LTP in diabetic rats (Reisi et al., 2017). Also, four weeks of fluoxetine injection $(0.7 \mathrm{mg} / \mathrm{kg})$ into the hippocampal $\mathrm{CA}_{1}$ reduced LTP and increased the presence of dendritic spines (Rubio et al., 2013). However, some study showed chronic fluoxetine administration increased short- and long-term plasticity in decreased neophobia in mice (Popova et al., 2017).

Due to the conflicting available results on the effect of fluoxetine on various forms of memory and learning as well as the lack of studies on the effect of fluoxetine on LTP in intact rats, the present study examined the effect of fluoxetine on the activity of the dentate gyrus (DG) cells using electrophysiological recording in intact rats.

\section{Materials and methods}

\section{Animals}

Eighteen adults' male Wistar rats (8 weeks old, $250 \pm 50 \mathrm{~g}$ ) were obtained from the Hamadan University of Medical Sciences. Animals were held under a 12-h light/dark period (lights on between 7:00AM and 7:00PM). Animal care, treatments, and surgery were approved by the Scientific Committees of Hamadan University of Medical Sciences (code of ethics committee: IR.UMSHA.REC.1386.53293) and conducted in accordance with the guidelines for the Care and Use of Laboratory Animals by the National Institutes of Health, USA (Publications NIH No. 85-23, amended 1985).

Rats were divided into three groups: the control group $(n=6)$ received saline $15 \mathrm{~min}$ before high-frequency stimulation (HFS) and the fluoxetine groups were treated with fluoxetine $2 \mathrm{mg} / \mathrm{kg}(\mathrm{n}=6)$ or $10 \mathrm{mg} / \mathrm{kg}(\mathrm{n}=6)$, $15 \mathrm{~min}$ before HFS.

\section{Drugs and the method of injection}

Fluoxetine hydrochloride was purchased from Recordati, Italy and dissolved in saline and after a steady-state baseline response, a single injection of saline or fluoxetine (2 and $10 \mathrm{mg} / \mathrm{kg}$; intraperitoneal [IP]) was done daily. Urethane was obtained from Sigma.

\section{Electrophysiological technique}

\section{Surgical method}

Rats were anesthetized using an IP injection of urethane $(1.5 \mathrm{~g} / \mathrm{kg})$. Then, the skulls were fixed in a stereotaxic device and the scalp was taken. In the skull, small holes were made with the dental drill. Through pushing the skin, the skull surface was exposed and the bipolar recording electrode was placed in the granular cells of the $\mathrm{DG}(\mathrm{AP}=-3.8 \mathrm{~mm} ; \mathrm{ML}=2.3 \mathrm{~mm}$; $\mathrm{DV}=3.2 \mathrm{~mm}$ posterior to bregma) and stimulating electrodes in the perforant pathway $(\mathrm{PP} ; \mathrm{AP}=-8.1 \mathrm{~mm} ; \mathrm{ML}=4.3 \mathrm{~mm} ; \mathrm{DV}=$ $3.2 \mathrm{~mm}$ posterior to bregma) were located according to the atlas of Paxinos and Watson. Using a protective heat 
pad (a controlled electrical heating blanket), the animals' body temperature was maintained at $37.0 \pm 0.2^{\circ} \mathrm{C}$ during operation. We used Teflon-coated bipolar wire electrodes (except for the tips) made of stainless steel $(125 \mu \mathrm{m}$ inner diameter $/ 175 \mu \mathrm{m}$ external diameter, Advent Co., UK), which were inserted into the DG or PP (Lashgari et al., 2008; Shahidi et al., 2018a).

\section{Electrophysiological recordings and LTP induction}

The electrodes were lowered slowly until a positive population spike (PS) amplitude appeared with the maximum response. Single-phase square-wave pulses $(0.2 \mathrm{~ms})$ were generated by a constant current isolation unit (A365, WPI, USA) and applied to the PP and the responses evoked in the DG. At the beginning of the experiment, an input-output curve with stimulus intensities ranging from 100 to $900 \mu \mathrm{A}$ was generated to determine the maximum PS amplitude, and then the intensity of the test stimulus was set at a level that evoked a PS amplitude of $40 \%$ of the maximum. After the final determination of electrode placement, a minimum of $30 \mathrm{~min}$ was considered to ensure stabilization of the signal. Following baseline response recording, HFS $(400 \mathrm{kHz}$, stimulus duration $0.2 \mathrm{~min}, 10$ bursts of 20 stimuli, $10-\mathrm{S}$ inter-burst interval) was performed in the PP rejoin. Then, evoked responses were noted at 5, 30, 60 and 120min after the HFS. Finally, the excitatory postsynaptic potential (EPSP) slope, PS amplitude and paired stimulation of recurrent interneurons were measured.

The PS amplitude was calculated as the difference between the initial peaks of the positive wave and the second negative wave. The EPSP slope was known to be the slope of the rising part of the first positive peak. The paired-pulse data were expressed as the ratio of the second response with respect to the first response in each sample (Karamian et al., 2015). Then, saline or fluoxetine was injected $15 \mathrm{~min}$ before a single excitation and subsequent response from paired stimulation was recorded and their values $15 \mathrm{~min}$ before and after the treatment were compared between three groups (Shahidi et al., 2019b).

The eTrace package (www.sciencebeam.com) was used to describe the stimulus features. Next, the potential field response was filtered $(1 \mathrm{~Hz}-3 \mathrm{kHz})$ in the DG after passing through a preamplifier for maintaining amplification (1000x; DAM 80, World Precision Instruments). Representative response traces are given before and after HFS for each group (Figure 1).

\section{Statistical analysis}

The findings are expressed as $\%$ mean \pm SEM. The experimental data were analyzed by SPSS version 16.0. PS amplitude and EPSP slope were analyzed using oneway ANOVA with Tukey's post-hoc test and recurrent inhibition of the hippocampus was assessed by paired t-test. The significance level was set at $P<0.05$. The recurrent of hippocampal inhibitory from the second stimulation to PS amplitudes from the first stimulation.

\section{Results}

Effects of fluoxetine on PS amplitude in the dentate gyrus using $100 \mathrm{~Hz}$ tetanic stimulation

PS amplitude exhibited a significant difference between groups. In fluoxetine $(10 \mathrm{mg} / \mathrm{kg})$ group, PS amplitude increased compared with the control group $5 \mathrm{~min}$ after HFS $[\mathrm{F}(2,15)=1.987 ; P<0.05]$. Also, 30min after tetanic stimulation, PS amplitude in the fluoxetine $(10 \mathrm{mg} / \mathrm{kg})$ group was higher than the fluoxetine $(2 \mathrm{mg} /$ $\mathrm{kg}$ ) group $[\mathrm{F}(2,15)=12.277 ; P<0.001]$. Furthermore, $\mathrm{PS}$ amplitude in the fluoxetine $(2 \mathrm{mg} / \mathrm{kg})$ group was higher than the control group $60 \mathrm{~min}$ after titanic stimulation $[\mathrm{F}(2,15)=3.37 ; P<0.05$; Figure 2].

Effects of fluoxetine on EPSP slope in the dentate gyrus using $100 \mathrm{~Hz}$ tetanic stimulation

Comparison of EPSP slope showed that there is no meaningful difference between groups $5 \mathrm{~min}[\mathrm{~F}(2,15)=$ $0.215 ; P=0.809], 30 \mathrm{~min}[\mathrm{~F}(2,15)=0.734 ; P=0.496]$ and $120 \mathrm{~min}[\mathrm{~F}(2,15)=0.395 ; P=0.68]$ after tetanic stimulation. However, EPSP slope in the fluoxetine $(10 \mathrm{mg} / \mathrm{kg})$ group 60min after tetanic stimulation increased compared with the control group $[\mathrm{F}(2,15)=0.739 ; P<0.05$; Figure 3].

Effects of fluoxetine on the recurrent inhibition in the $D G$ of the hippocampus

Recurrent inhibition of the hippocampal interneurons was obtained by dividing the PS amplitude of the second stimulation by the PS amplitude of the first stimulation. There was no significant difference in the recurrence inhibition before and after intraperitoneal injection at $30 \mathrm{~min}$ after HFS (Fig. 4). Before: Saline $=50 \pm 7$, Fluoxetine $2 \mathrm{mg} / \mathrm{kg}=52 \pm 8$, Fluoxetine $10 \mathrm{mg} / \mathrm{kg}=54 \pm 6$. After: Saline $=52 \pm 9$, Fluoxetine $2 \mathrm{mg} / \mathrm{kg}=40 \pm 9$, Fluoxetine $10 \mathrm{mg} / \mathrm{kg}=47 \pm 9$. 

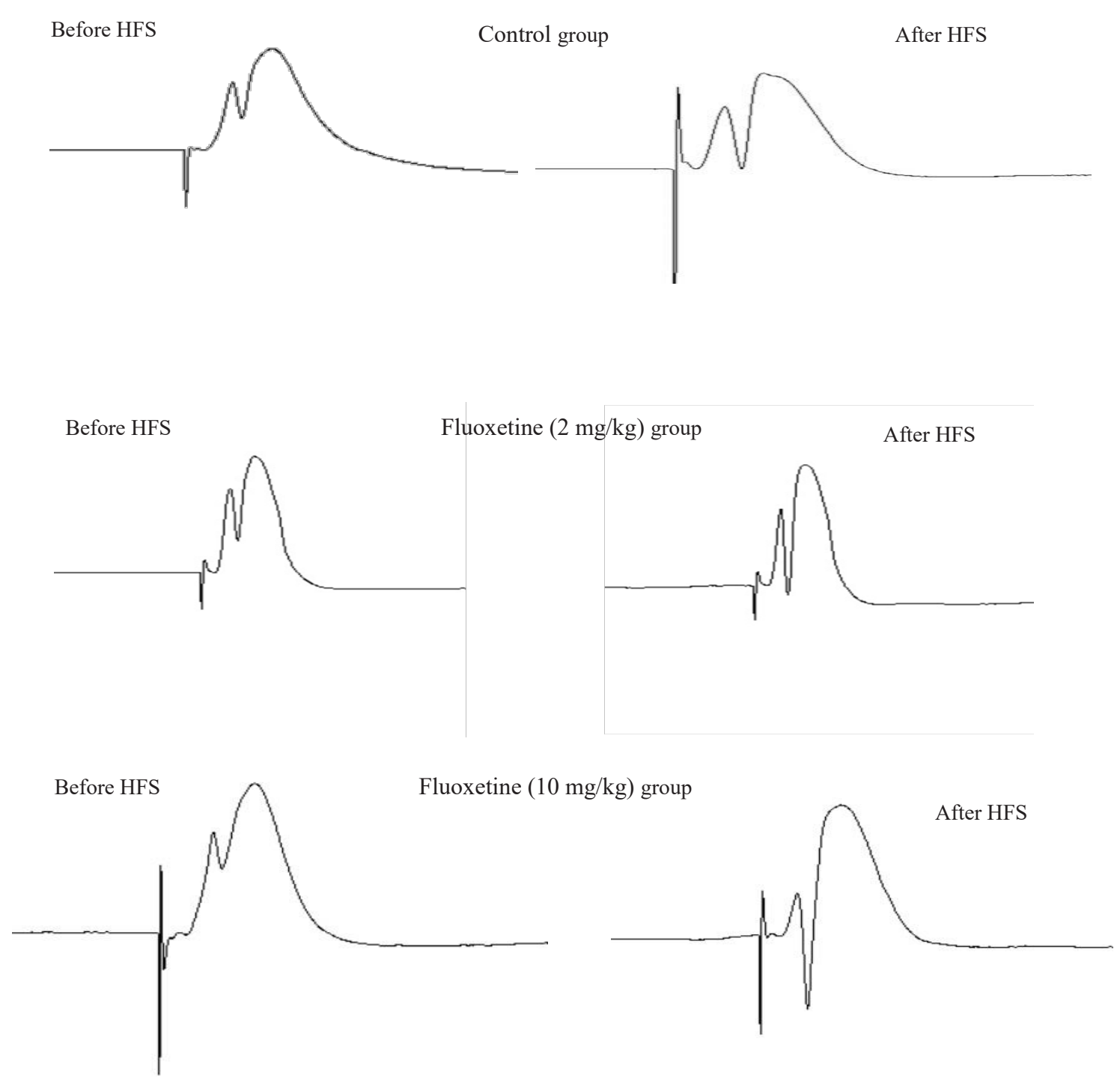

FIGURE 1. Sample traces of PS amplitude and fEPSP slope recorded in PP-DG prior to and after HFS. PS: population spike; EPSP slope: excitatory postsynaptic potential slope; PP: perforant pathway; DG: dentate gyrus; HFS: high-frequency stimulation.

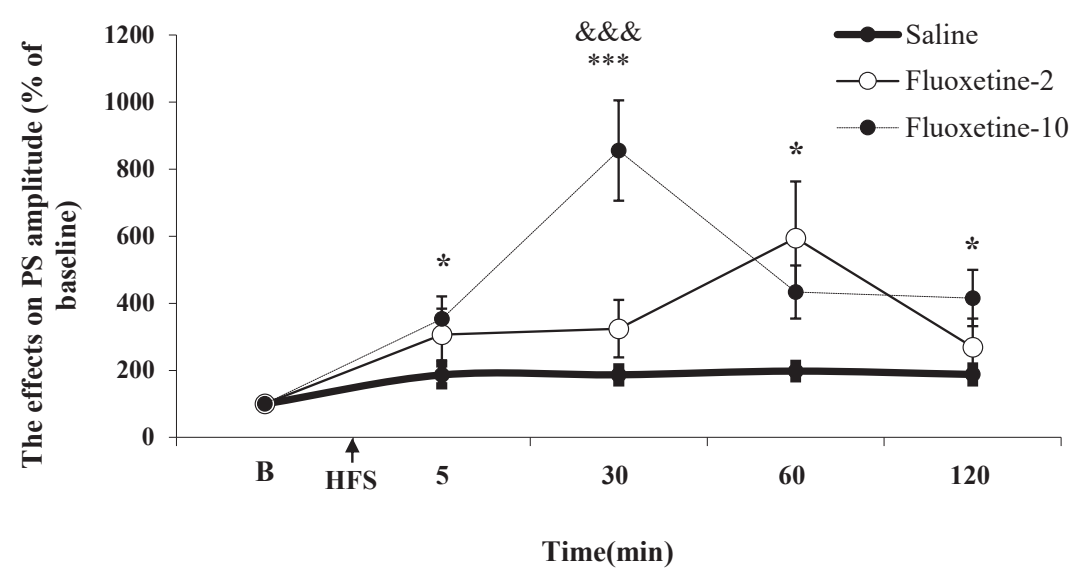

FIGURE 2. S Comparison of the magnitude of PS amplitude in the dentate gyrus after administration of fluoxetine $(2 \mathrm{and} 10 \mathrm{mg} / \mathrm{kg}$; IP) or saline. At 5, 30, 60 and $120 \mathrm{~min}$, the recording was done in response to stimulation following an HFS. Data are expressed as \%mean \pm SEM. ${ }^{*} P<0.05$ and $^{* *} P<0.01$ compared with the control group; \&\&\& $P<0.01$ compared with the fluoxetine $(2 \mathrm{mg} / \mathrm{kg})$ group (n= 6). PS: population spike; high-frequency stimulation (HFS). 


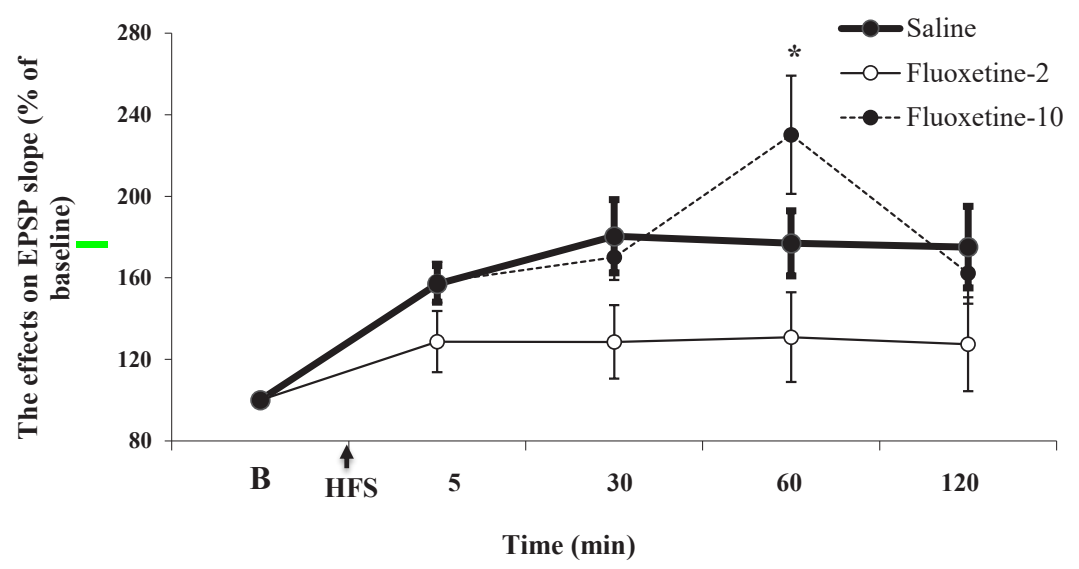

FIGURE 3. Comparison of EPSP slope before and $15 \mathrm{~min}$ after treatment between the control and fluoxetine ( 2 and $10 \mathrm{mg} / \mathrm{kg}$; IP) groups in the dentate gyrus. Data are expressed as $\%$ mean $\pm \operatorname{SEM}(n=6)$. The changes in EPSP slope in each group were noted and the value of EPSP slope was considered $100 \%$ in each group. ${ }^{*} P<0.05$ compared with the control group. EPSP slope: excitatory postsynaptic potential slope.

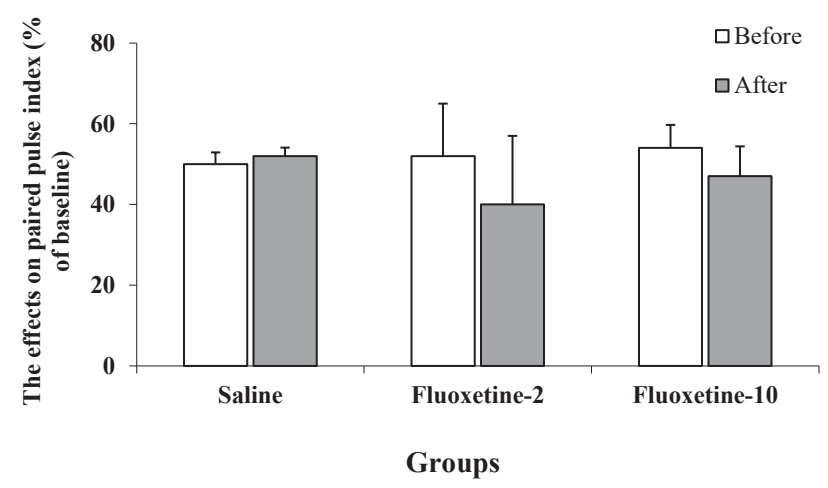

FIGURE 4. Effect of fluoxetine on recurrent inhibition of interneurons of the dentate gyrus was obtained from PS amplitude divided by the second stimulation compared with the PS amplitudes from the first stimulation. The amount of recurrent inhibition before and after injection at 30min after HFS showed no significant difference between groups.

\section{Discussion}

In the present study, the effects of acute IP administration of fluoxetine, as one of the most common selective serotonin reuptake inhibitors, were evaluated on LTP induction in hippocampal DG in intact rats. The results showed that (1) fluoxetine $(2 \mathrm{mg} / \mathrm{kg})$ increased PS amplitude compared with the control group; (2) PS amplitude in the fluoxetine $(10 \mathrm{mg} / \mathrm{kg})$ group was higher than in the fluoxetine $(2 \mathrm{mg} / \mathrm{kg})$ group; (3) EPSP slope showed an increase in the fluoxetine $(10 \mathrm{mg} / \mathrm{kg})$ group $60 \mathrm{~min}$ after HFS compared with the control group; (4) recurrent inhibition of DG was not affected by fluoxetine.

Fluoxetine is one of the selective serotonin reuptake inhibitor antidepressants used to treat depression in particularly persistent or severe cases, and also is used for cognitive behavioral therapy (Marken and Munro, 2000). Chronic fluoxetine injection increased neurogenesis in the DG (Ohira et al., 2019).

Our results showed that the systemic administration of fluoxetine (2 and $10 \mathrm{mg} / \mathrm{kg}$ ) had no effect on basal synaptic transmission in the DG. However, this drug during the tetanic excitations could modulate synaptic plasticity. Thus, both doses, particularly high-dose fluoxetine caused a larger EPSP slope and PS amplitude than the saline group 120min after HFS. Some reports have shown different effects of fluoxetine due to its interaction with different postsynaptic receptors (Meneses and Hong, 1995).

In agreement with our results, Ohashi et al. (2002) recorded that 21 days of treatment with fluvoxamine improved LTP in the hippocampal-prefrontal pathway. However, similar treatment did not affect LTP in the amygdaloid complex by stimulating the medial prefrontal cortex (Ohashi et al., 2003). In contrast to our research, in vitro hippocampal slices were impaired by chronic treatment with antidepressants (venlafaxine and imipramine) that prevent both serotonin and norepinephrine reuptake; this impairment is due to changes 
downstream of postsynaptic depolarization and calcium influx (Cooke et al., 2014).

In addition, Stewart and Reid (2000) showed a decrease in LTP in the DG in animals that received fluoxetine for 15 days. Wang et al. (2008) stated that fluoxetine treatment decreased LTP in DG in vitro after 5 days of treatment; however, LTP increased after 25 days of treatment. A similar improvement of LTP was observed in the mice DG slices after 28 days of fluoxetine treatment (Bath et al., 2012). In contrast, no effect on LTP was found after 7 or 21 days of citalopram treatment; but LTP inhibition was observed 7 or 21 days of venlafaxine treatment (Cooke et al., 2009). It appears that inhibition of LTP results from increased GABA receptor function (Cooke et al., 2014).

Also, measurement of recurrent inhibition indicated the inhibition of inhibitory interneurons affecting the activity of the DG region by fluoxetine. This effect was induced by fluoxetine and was not achieved by affecting the inhibitory interneurons in the DG, but it was due to a direct effect on the PP-DG pathway.

In agreement with this study, escitalopram (a serotonin reuptake inhibitor) did not affect synaptic basal transmission in the $\mathrm{CA}_{1}$ region of the hippocampus (Mnie-Filali et al., 2006). However, Stäubli and Xu (1995) showed that the administration of 5-HT $\mathrm{HT}_{3}$ receptor antagonists, such as ondansetron significantly increased the magnitude and duration of LTP compared with the vehicle injection in the hippocampus $\mathrm{CA}_{1}$ of free-moving rats. This difference with our results may be due to the target areas and different serotonin receptors. The results of the electrophysiological recording of $50-70 \%$ of the impaired DG region in mice showed that administration of fluoxetine $(5 \mathrm{mg} / \mathrm{kg}$; for 42 days [once daily]) had no effect on the LTP induction (Keith et al., 2007). Also, another study indicated that fluoxetine could not significantly affect the activation of more cells (Keith et al., 2007). This result is not consistent with our results. Regular consumption of chronic or acute fluvoxamine, another serotonin reuptake inhibitor, could increase memory and synaptic plasticity dose-dependently in the prefrontal cortex and hippocampus, and repeated administrations were more effective and with long-term effects (Ohashi et al., 2002).

The effects of serotonin on LTP induction caused an improvement in memory and learning in biological models. Considering the dose-dependent effect ob- served in other studies by different antidepressants, their results are consistent with our results and indicate that serotonin reuptake inhibitors at higher doses are more effective in synaptic plasticity. Therefore, fluoxetine treatment increased synaptic plasticity and dendritic spine remodeling induced the growth of cerebrocortical synapses (Rubio et al., 2013). LTP, as a form of synaptic plasticity, has been regarded as a critical cellular mechanism underlying learning and memory (Shahidi et al., 2019a).

\section{Conclusion}

Overall, our results showed that the enhancement of the activation of the serotoninergic system in the DG, induced long-term potentiation, especially at higher doses. Also, LTP represents a valid molecular and cellular model for learning and memory. Thus, fluoxetine can be considered an effective agent in learning and memory.

\section{Acknowledgments}

The authors thank the staff of Physiology Department, Hamadan University of Medical Sciences for helping us with this project. It was supported by a grant (Grant number: No 53293).

\section{Conflict of interest}

The authors declare no conflicts of interest.

\section{References}

Bacqué-Cazenave J, Bharatiya R, Barrière G, Delbecque JP, Bouguiyoud N, Di Giovanni G, et al. Serotonin in animal cognition and behavior. Int J Mol Sci 2020; 21: 1649. https://doi.org/10.3390/ijms21051649

Bath KG, Jing DQ, Dincheva I, Neeb CC, Pattwell SS, Chao MV, et al. BDNF Val66Met impairs fluoxetine-induced enhancement of adult hippocampus plasticity. Neuropsychopharmacology 2012; 37: 1297-304. https://doi.org/10.1038/npp.2011.318

Baudry M. Long-term Potentiation (Hippocampus). In: Smelser NJ, Baltes PB, editors. International encyclopedia of the social \& behavioral sciences. Oxford: Pergamon, 2001, p. 9081-3. https://doi.org/10.1016/B0-08-0430767/03435-5

Catapano LA, Manji HK. G protein-coupled receptors in major psychiatric disorders. Biochim Biophys Acta Biomembr 2007; 1768: 976-93. https://doi.org/10.1016/j.bbamem.2006.09.025 
Cooke JD, Cavender HM, Lima HK, Grover LM. Antidepressants that inhibit both serotonin and norepinephrine reuptake impair long-term potentiation in hippocampus. Psychopharmacology 2014; 231: 4429-41. https://doi. org/10.1007/s00213-014-3587-1

Cooke JD, Grover LM, Spangler PR. Venlafaxine treatment stimulates expression of brain-derived neurotrophic factor protein in frontal cortex and inhibits long-term potentiation in hippocampus. Neuroscience 2009; 162: 1411-9. https:// doi.org/10.1016/j.neuroscience.2009.05.037

Dringenberg HC. The history of long-term potentiation as a memory mechanism: controversies, confirmation, and some lessons to remember. Hippocampus 2020; 30: 9871012. https://doi.org/10.1002/hipo.23213

Hamilton TJ, Kwan GT, Gallup J, Tresguerres M. Acute fluoxetine exposure alters crab anxiety-like behaviour, but not aggressiveness. Sci Rep 2016; 6: 1-6. https://doi. org/10.1038/srep19850

Karamian R, Komaki A, Salehi I, Tahmasebi L, Komaki H, Shahidi S, et al. Vitamin C reverses lead-induced deficits in hippocampal synaptic plasticity in rats. Brain Res Bull 2015; 116: 7-15. https://doi.org/10.1016/j.brainresbull.2015.05.004

Keith JR, Wu Y, Epp JR, Sutherland RJ. Fluoxetine and the dentate gyrus: memory, recovery of function, and electrophysiology. Behav Pharmacol 2007; 18: 521-31. https://doi. org/10.1097/FBP.0b013e3282d28f83

Kobayashi K, Ikeda Y, Haneda E, Suzuki H. Chronic fluoxetine bidirectionally modulates potentiating effects of serotonin on the hippocampal mossy fiber synaptic transmission. J Neurosci 2008; 28: 6272-80. https://doi.org/10.1523/ JNEUROSCI.1656-08.2008

Lashgari R, Khakpour-Taleghani B, Motamedi F, Shahidi $\mathrm{S}$. Effects of reversible inactivation of locus coeruleus on long-term potentiation in perforant path-DG synapses in rats. Neurobiol Learn Mem 2008; 90: 309-16. https://doi. org/10.1016/j.nlm.2008.05.012

Lynch MA. Long-term potentiation and memory. Physiol Rev 2004; 84: 87-136. https://doi.org/10.1152/physrev.00014.2003

Marken PA, Munro JS. Selecting a selective serotonin reuptake inhibitor: clinically important distinguishing features. Prim Care Companion J Clin Psychiatry 2000; 2: 205-210. https://doi.org/10.4088/PCC.v02n0602

Marwari S, Dawe G. (R)-fluoxetine enhances cognitive flexibility and hippocampal cell proliferation in mice. J Psychopharmacol 2018; 32: 441-57. https://doi.

\section{org/10.1177/0269881118754733}

Meneses A, Hong E. Effect of fluoxetine on learning and memory involves multiple 5-HT systems. Pharmacol Biochem Behav 1995; 52: 341-6. https://doi.org/10.1016/00913057(95)00102-3

Mnie-Filali O, El Mansari M, Espana A, Sànchez C, Haddjeri N. Allosteric modulation of the effects of the 5-HT reuptake inhibitor escitalopram on the rat hippocampal synaptic plasticity. Neurosci lett 2006; 395: 23-7. https://doi. org/10.1016/j.neulet.2005.10.044

Molaei A, Hatami H, Dehghan G, Sadeghian R, Khajehnasiri N. Synergistic effects of quercetin and regular exercise on the recovery of spatial memory and reduction of parameters of oxidative stress in animal model of Alzheimer's disease. Excli J 2020; 19: 596-612.

Ohashi S, Matsumoto M, Otani H, Mori K, Togashi H, Ueno $\mathrm{K}$, et al. Changes in synaptic plasticity in the rat hippocampo-medial prefrontal cortex pathway induced by repeated treatments with fluvoxamine. Brain Res 2002; 949: 131-8. https://doi.org/10.1016/S0006-8993(02)02973-6

Ohashi S, Togashi H, Matsumoto M, Mori K, Ueno K, Yoshioka M. Changes in synaptic properties in cortical-limbic communications induced by repeated treatments with fluvoxamine in rats. J Pharmacol Sci 2003; 92: 100-7. https:// doi.org/10.1254/jphs.92.100

Ohira K, Hagihara H, Miwa M, Nakamura K, Miyakawa T. Fluoxetine-induced dematuration of hippocampal neurons and adult cortical neurogenesis in the common marmoset. Mol Brain 2019; 12: 69. https://doi.org/10.1186/s13041019-0489-5

Pawluski JL, van Donkelaar E, Abrams Z, Houbart V, Fillet M, Steinbusch HW, et al. Fluoxetine dose and administration method differentially affect hippocampal plasticity in adult female rats. Neural Plast 2014; 2014: 123026. https:// doi.org/10.1155/2014/123026

Popova D, Castrén E, Taira T. Chronic fluoxetine administration enhances synaptic plasticity and increases functional dynamics in hippocampal CA3-CA1 synapses. Neuropharmacology 2017; 126: 250-6. https://doi.org/10.1016/j.neuropharm.2017.09.003

Reisi P, Sepahvand F, Zarei G, Kamali Dolatabadi L, Haghjooye Javanmard S, Alaei H. Effects of amitriptyline and fluoxetine on synaptic plasticity and TNF- $\alpha$ level at hippocampus of streptozotocin-induced diabetic rats. Physiol Pharmacol 2017; 21: 137-46.

Rubio FJ, Ampuero E, Sandoval R, Toledo J, Pancetti F, Wyneken U. Long-term fluoxetine treatment induces input-spe- 
cific LTP and LTD impairment and structural plasticity in the CA1 hippocampal subfield. Front Cell Neurosci 2013; 7: 66. https://doi.org/10.3389/fncel.2013.00066

Sadeghian R, Fereidoni M, Soukhtanloo M, Azizi-Malekabadi H, Hosseini M. Decreased nitric oxide levels in the hippocampus may play a role in learning and memory deficits in ovariectomized rats treated by a high dose of estradiol. Arq Neuropsiquiatr 2012; 70: 874-9. https://doi. org/10.1590/S0004-282X2012001100010

Shahidi S, Komaki A, Sadeghian R, Asl SS. Different doses of methamphetamine alter long-term potentiation, level of BDNF and neuronal apoptosis in the hippocampus of reinstated rats. J Physiol Sci 2019a; 69: 409-19. https://doi. org/10.1007/s12576-019-00660-1

Shahidi S, Komaki A, Sadeghian R, Asl SS. Effect of a 5-HT1D receptor agonist on the reinstatement phase of the conditioned place preference test and hippocampal longterm potentiation in methamphetamine-treated rats. Brain Res 2018a; 1698: 151-60. https://doi.org/10.1016/j.brainres.2018.07.030

Shahidi S, Mehrpour O, Sadeghian R, Asl SS, Komaki A. Alteration level of hippocampus BDNF expression and longterm potentiation upon microinjection of BRL15572 hydrochloride in a rat model of methamphetamine relapse. Brain Res Bull 2019b; 148: 18-24. https://doi.org/10.1016/j. brainresbull.2019.03.008

Shahidi S, Sadeghian R, Komaki A, Asl SS. Intracerebroventricular microinjection of the 5-HT1F receptor agonist LY 344864 inhibits methamphetamine conditioned place preference reinstatement in rats. Pharmacol Biochem Behav 2018b; 173: 27-35. https://doi.org/10.1016/j. pbb.2018.08.001

Stäubli U, Xu FB. Effects of 5-HT3 receptor antagonism on hippocampal theta rhythm, memory, and LTP induction in the freely moving rat. J Neurosci 1995; 15: 2445-52. https:// doi.org/10.1523/JNEUROSCI.15-03-02445.1995

Stewart CA, Reid IC. Repeated ECS and fluoxetine administration have equivalent effects on hippocampal synaptic plasticity. Psychopharmacology 2000; 148: 217-23. https:// doi.org/10.1007/s002130050045

Valluzzi JA, Chan K. Effects of fluoxetine on hippocampal-dependent and hippocampal-independent learning tasks. Behav Pharmacol 2007; 18: 507-13. https://doi.org/10.1097/ FBP.0b013e3282ee2a91

Wang JW, David DJ, Monckton JE, Battaglia F, Hen R. Chronic fluoxetine stimulates maturation and synaptic plasticity of adult-born hippocampal granule cells. J Neurosci 2008; 28: 1374-84. https://doi.org/10.1523/JNEUROSCI.3632-07.2008 